\title{
Free Education Policy and its Emerging Challenges in Sri Lanka
}

\author{
Kingsley Karunaratne Alawattegama \\ University of Sri Jayewardenepura, Sri Lanka
}

Doi: $10.19044 /$ ejes.v7no1a1

URL:http://dx.doi.org/10.19044/ejes.v7no1a1

\begin{abstract}
Education system plays a very crucial role in any country towards achieving a sustainable development and strengthening social, cultural, historical and integral development, and is often called as the back born of the society. Producing competent graduate, professional or technical expert and a responsible citizen enriched with social and cultural values, which eventually enhances the quality of a country's workforce, is one of the ways the education system contributes to the development of a country. Giving the due recognition to the importance of the education system that paves the way for integral development of a country, some countries have practiced and promotes a free education policy. The purpose of this paper is to explore the salient features and its evolution of the free education system in Sri Lanka and its emerging challenges for policy makers. This paper also aims at suggesting alternative strategies to overcome the challenges that are emerging from the changing global market context by pooling of views and ideas of academics and other experts in the field of education. This study expects to suggest alternative strategies to overcome the emerging issues in the free education system that would add value to the policy makers to objectively develop future strategies and policies relating to the education system of the country. In order to achieve the aforesaid objective, this study explores the existing literature relating to education systems and experts' views and authors' own experience as academics. This study demonstrates that the Sri Lankan education system requires an urgent reform to revise on a holistic approach to address emerging issues in the areas of policy making level, implementation level and supervisory and regulatory level. This study recommends providing annually a six percent from the GDP for the state education, eliminating disparities between rural and urban popular schools, timely revision of general school curriculum in order to make it best fit the changing world, promoting student centered and participatory learning environment, protecting the higher education right of the qualified students who are not absorbed by the state universities and protecting and enhancing the economic, career and social
\end{abstract}


welfare of the school teachers as the key areas that the policy makers must pay their close and urgent attention.

Keywords: Education, Education policy, Free education, School education, Sri Lanka.

\section{Introduction}

People learn from birth to death; hence it is said that 'learning' is a lifelong journey. There are different types of education, it maybe formal or informal. As far as the success of the formal education system of a country is concerned, its status of the democracy is very crucial as only in Democratic Societies and States there is an attention on education that develop personal, citizenship and professional dimension considering rights and duties of the people. Education system plays a crucial role in any country towards achieving a sustainable development and could be treated as the backbone of any civilized society. Schools, universities and other educational institutes can contribute immensely towards sustainable development of a country by enhancing the knowledge, skills, attitude and competencies of its workforce. Producing competent graduate, professional or technical expert and a responsible citizen enriched with social and cultural values, which eventually enhances the quality of a country's workforce, is one of the ways the education system contributes to the development of a country. While gaining the access to a formal education system has been a difficult or expensive exercise for the people in many countries, Sri Lankan government, since 1944, initiated a free education system for the public without any discrimination. The concept of free education system was initiated by honorable C W W Kannangara as the minister for education in the state council of Sri Lanka (formerly Ceylon) which was a paradigm shift in the education system in Sri Lanka. The significant influence of his free education policy resulted on the Sri Lanka state education system led him to being commonly referred as the father of the free education in Sri Lanka.

It is often seen that the term 'free education' is being narrowly defined misinterpreted by many people. The most common and popular misinterpretation is "the education that is offered free of charges". It is free such way where every citizen is enabled to access the formal national education system and letting all the citizens of the country an equal opportunity to take a part of it in order to develop a cultivated and responsible citizen. According to Jayawardena (2013), "Free Education is not only to provide 'education' at free of cost, but to provide equitable access to every child irrespective of the demography, exploit the individual strengths and cultivate good values to become a law-abiding citizen". The objective of this paper is to explore the salient features of the free education system in Sri 
Lanka, its milestones, current achievements and its emerging challenges and contemporary issues and, where appropriate, providing some recommendations for policy makers to counter those challenges. For this purpose, this study explores the free education policies and its implications in the context of the school education system of Sri Lanka.

It is seen that the government policy on the free education system of the country has been very sensitive topic for any political party who are contesting for general elections. Any explicit, implicit, or perceived threat to the free education system would certainly result a fatal blow for any political propaganda. During the recent past no governments have made some considerable attempts to reform this sector as it is politically sensitive. Nevertheless, there are some evidence of providing some band-aid solutions disguising the real agenda under the "socialist framework" (Jayawardena, 2013). This implies both general public and policy makers are equally paying careful attention to the free education. However, it is seen while the people concern about the quality of the education, the government and the policy makers concern more on the expense and the burden on the government budget under the heading of the education.

\section{The role of an education system in a society}

The role of education in creating, preserving and sustaining the right knowledge, skills and attitudes in the context of the social value system are crucial for the wellbeing of any civilized society. Education systems, in general, focus on creating and dissemination of knowledge, skills and values with the view of developing and empowering a holistic and a responsible citizen. This enables them to contribute towards creating and enhancing the wellbeing of the society as a whole. The focus of the world, towards achieving the development over the time, has shifted its strategic intent from physical resources to human resources, and from information to knowledge society. In today's context, it is said that the people are living in a knowledge society where the information and knowledge plays a crucial role in the social systems towards gaining strategic and competitive advantages for a country. In a knowledge society, education system facilitates to transfer and sustain the knowledge and the social value system over generations.

Education system of a country, while it influences the wellbeing of the society in many ways, plays a crucial role in improving the quality of human resource, in particular, that directly influences the quality of the workforce and adding value to the economy. The view of human resources as a form of capital is not new, but it has only recently been thoroughly examined and explicitly incorporated into the stream of economic thought (Schultz, 1971). According to Green, A (1997), the role of the national state and with it the place of education is now changing. Griffin, Care and McGaw (2012) emphasize that 
following a growing awareness that many countries are moving from an industrial-based to information-based economy and that education systems must respond to this change. In this context education system influences labor market outcomes with institutional settings in which such theories provide the most likely mechanism (Werfhorst, 2011). This implies that the education has a big role to play in a society in creating, preserving and transforming the knowledge over generations. It is evident that few studies have been conducted on the role of national policy makers towards uplifting the quality of educations systems in colleges and higher education institutes. According to Steven Mintz (2014), Educational system can serve as innovation incubators and it should take steps towards advancing next-generation online learning, which will play a critical role in enhancing access, affordability, student success, and institutional sustainability; and leading the way as institutions gradually develop outcomes-driven, competency-based, career-oriented educational pathways. These suggest that a traditional education system needs a complete turnaround to cope with the emerging dynamic needs of the society.

\section{Status of the education system of Sri Lanka prior to the implementation of free education policy.}

Sri Lankan traditional and orthodox education systems have been inspired and highly influenced by the Buddhist doctrines. The literature supporting to the traditional educational systems of Sri Lanka provides evidence that the Sri Lankan education system, prior to colonization, has been centralized to the Buddhist temples some of which later became Pirivenas. The Pirivenas were primarily meant for Buddhist clergy, but of the sons of the royal families and chieftains also attended for their secondary education (Hevawasam 1969). Ancient Sri Lankan's traditional life was not complex, and many people engaged in farming as their main livelihood. Technology used in farming also very orthodox and environmentally friendly. These basic technologies and related knowledge were transferred over the generations through socialization process from adults to young generations. According to David \& Sethunga (2011) most Sri Lankan children did not proceed beyond elementary education and started learning some of arts or crafts to prepare for life. A farmer's son became an apprentice of the father; a mason / carpenter's son became an apprentice of his father or uncle.

Sri Lankan traditional Pirivenas based education system was collapsed to a greater extent during the British colonization period. British governors promoted Western Education promoting western culture and established several private schools to produce state workers who can speak English and embrace English values and Western culture. While the English rulers promote the Western and English education in the country, some Sinhalese 
movement initiated demanding the right to education for all. This social pressure group emerged as the "Colombo Buddhist Theosophical Society" lead by Anagarika Dharmapala who was well supported by Colonel Henry Steel Olcott an American inspired by the Buddhist teaching. This Buddhist pressure group managed to establish several Buddhist Schools in different parts of the country such as Dharmaraja, Ananda, Nalanda, Dharmapala, Mahinda and Maliyadewa for boys and Mahamaya, Vishaka, Sangamiththa for girls. These schools, among others, play a leading role in Sri Lankan school education systems since then.

Census report of 1901 provides evidence that the Sri Lankan education system in the $19^{\text {th }}$ century has been worsening in many fronts. According the census report, as cited by David et.al (2011), out of 867,103 children; 650,000 did not attend schools due to lack of facilities. Due to the weak relationship between the English governors and Buddhist temples funding and support were not extended by the British rulers for enhancing the education in the rural areas. The report further reveals that 60 percent of the males and 90 percent of the females in the colony were still illiterate.

\section{Government policies on the provision of free education and its key milestones.}

The introduction of free education policy in 1944 was a paradigm shift in the history of the education system in Sri Lanka. The political environment for implementing this policy was emerging as a result of the Dhonomore Commission reforms which came into effect from 1930. The implementation was by the Chair of Executive committee and the government of Sri Lanka initiated the concept of universal free education policy in 1945 aiming to provide equal opportunity for all to gain access to the education system and establishing a strong foundation for long term sustainable development in the human capital of the country. This policy initiative has been relayed and sustained by the successive governments with some innovative experiments. The government policies on the provision of the free text book program, free uniform program, Navodya school development program, free midday meal program, transportation subsidy program, grade five scholarship program, Mahapola scholarship program, Mahindodaya Laboratory and Development program have progressively contributed towards ensuring and the quality of the national education system of the country.

Except for Mahapola scholarship program which is relevant to the state university students of the country all most all the other programs and policy decisions relevant to the primary and secondary school education of the country. This paper expects to explore the success and challenges of key government policy decisions and programs that are related to the school education of Sri Lanka implemented after1980. 


\section{Key government policy decisions on school education implemented since 1980 and their impact on school education system of Sri Lanka.}

All the governments that came to the power, since independence, have paid a keen interest in developing and improving the school education in Sri Lanka. As far as the policy decisions made by the governments in the name of free education are concerned the launching of free school text book program has been a crucial policy decision in the history of the free education system. The free text book program was launched with the objective of enhancing education quality and improving learning outcomes, particularly among children from poor families. Under this program, all students from grades 1 to 11 are provided with required text books free-of-charge by the government (Ganga M. Thilakarathne). Though it is seen government has to incur huge costs on this program accepting a considerable burden to the annual budget policy makers sees this program is one of the vital and the symbolic pillar in the free education system in Sri Lanka and not expects to curtail down its quality against cost. Nearly 4 million students, in grades $1-11$ in over 10,000 government schools around the country, benefit every year from the Free School Textbook Program. Currently over 20 million textbooks, covering about 250 different subjects, are distributed annually under the program (Ganga M. Thilakarathne). Offering school text books for the school children for free of charge has encouraged and motivates students from poor families to attend school and enjoy the benefits of the free education system. Literature provides evidence that implementation of the free text book program has enhanced the enrolment rate of the students and the overall literacy rate of the country.

Free School Uniform Program that was implemented in 1993 aims at giving the students from grade 1 to 13 with a free school uniform. The type of material and the quantity received by students depends on the gender and the grade in School (Ganga M. Thilakarathne, 2006). The free school uniform program created a big positive impact on reducing student absenteeism and a great relief for the poor parents. Currently, many students from poor families have directly benefited from this program and government incurs a significant amount of funds on this annually from its recurrent expenditure on education. The Free School Uniform Program also provides benefits to approximately 4 million students, from 1-13, in over 10,000 government schools and about 600 Pirivenas schools (Ganga M. Thilakarathne, 2006).

The Navodya School Development Programme was first implemented in 1997 with the view of providing rural schools with required infrastructures and other aiding equipment. The objective of this programme was to ensure the students in the rural and less privilege areas are not underprivileged anymore and receives a quality education. Under this programme, it was expected to construct and develop at least one school for each Divisional 
Secretariat. This program provided the schools with new buildings, laboratories, class rooms, libraries, etc. According to Ganga M. Thilakarathne, Navodya School Development Program aims at reducing regional disparities in education and providing quality education to rural students. It sought to develop at least one school from every DS division in the country to provide high quality education facilities. It is quite apparent that due to the funding problems and financial pressure and burden on the annual budget program has been interrupted by the lack of funds. The literature supports the provision of free school textbooks and uniforms, and the Navodya school development programme, have contributed towards improving school enrollment and attendance among the poor communities, and increasing the quality of education received by the students of the less privileged societies.

Mahindodaya programme that aimed at developing thousand secondary schools was launched in 2012 with the objective of eliminating the discriminations between the urban popular schools and the rural schools. This programme was one of the greatest programmes implemented by the ministry of education under the leadership of the former President Mahinda Rajapaksha that delivered tangible benefits to rural schools while many of other projects just limited to policy papers. Under this programme thousand secondary schools were selected on a provincial basis and equipped with computer unit, language unit, mathematics and science unit and distance learning center (Nenasa Center). This programme was implemented in line with the government vision of making Sri Lanka as the education of hub is Asia. With Mahindodaya thousand secondary school development programme it was expected to have a radical change in the Sri Lankan secondary school system. With these program policy makers expected to bring the technology to the village level and create opportunities for students in the rural area to conquer the world with novel technology.

\section{Emerging challenges in the free education system and recommendations for policy makers}

Sri Lankan free education system, though it has pushed the country forward into a leading position in the South Asian region in terms of literacy rate, school enrollment rate, gender parity in education, human quality index, etc., has been criticized for not being progressively improved and developed for a long time to cope with the changing world. While some scholars criticize the policies and policy makers in this regards some scholars emphasize the weakness of the policy implementation. The absence of strong and clear-cut policy framework of state education which is consistently implemented irrespective of which ruling party govern the country has been a critical issue that need a close attention. According to Jayewardene (2013) the government has failed to create an effective regulatory framework in a timely manner, thus 
leaving room in adding another layer to the existing "well known" hierarchical schooling system. The absence of such national regulatory framework is highly regrettable and dilutes the impetus for education.

It seems that political executives (cabinet ministers) seek to change and implement new education policies on an ad-h basis as and when the ruling party gets changed in the country. This creates a critical threat to the national education system of the country since it hinders implementing a long-term national education policy in a consistent manner. Further, it is apparent that there are many instances of conflicts between the professional executives (state employees) and the political executives when it comes to implement education policies. It is recommended to give more freedom and autonomy to the professional executives who possess required competency and the expertise for developing and implementing consistent and long-lasting policies that best fit for the changing world.

According to the Central Bank reports, it clearly provides evidence that there is a continuous budgetary cut down in the annual budgetary provision for the state education sector. University lecturers and other social pressure groups demands and emphasizes the importance of allocating 6\% of the GDP for the state education sector. The suggested increase in the annual budgetary provision for the education sector is a must to ensure the quality of the free education system in Sri Lanka. It is recommended to pay closer attention to the demand of the academicians for increasing the budgetary provision for the state education up to $6 \%$.

The free education policy was introduced to allow all the children in the country an equal opportunity to receive formal education. The disparity between geographical regions in education is another key problem that stimulus several adverse consequences in the primary and secondary education system in Sri Lanka. The Presidential Commission on Youth Unrest (1993) highlights "unfair distribution of schooling facilities between urban and rural sectors" as the main cause for the youth unrest and uprising against government during 1987-89. So, it is recommended for the policy makers to pay a careful attention to eliminate or minimizing the disparities in the facilities between the rural and urban schools. Improving the infrastructure facilities of the schools is a must in ensuring that students and the teachers are provided with a learning friendly environment and enhancing their pride and dignity and not being less privileged compared to the facilities enjoyed by the students of the urban popular schools.

The disparity between rural and urban popular schools creates a huge competition among parents for sending their children to the urban popular schools. It has been a big burden and stressful process for the parents to admit their children to grade one. It is recommend establishing a clear and transparent procedure for the admission of the grade one students to schools 
and eliminating the opportunities for possible corruptions, malpractices and reducing the prevailing pressure on the parents with respect to the grade one admission. A sustainable solution, in this regard, would be the development and the allocation of more resources to less privileged schools and minimizing the discriminations between the popular schools in the city and the rural lessprivileged schools.

Sri Lankan parents are highly concerned about their children's education and ready to spend their ultimate penny for the sake of their children's education. Sri Lankan culture is highly education oriented rather than consumption and entertainment oriented. As a result, a significant proportion of the household income is spent by the parents on their children's education despite the education is said to be free in Sri Lanka. It has been a long dream of most of the parents to send their children to a state university. However, according to the reports of the Department of Census and Statistics there are about 300,000 students annually sit for the Advanced Level Examination and approximately only a sixty percent of them are qualified for the university entrance. Nevertheless, out of these qualified students just about $15 \%$ are selected to the state universities of Sri Lanka leaving the rest of the people $(85 \%)$ losing their dream to enter state university education. In addition to this student population, there is an additional student intake annually adding to this from the international schools. This gives an increasing pressure from the society as to what opportunities should be made available for these qualified young-blood to ensure their higher education rights are protected.

The free education system is a mechanism that aims at ensuring the education right of the people and providing equal opportunity for all, including those who are willing and able to pay for a better education, an access to the higher education services. During the recent past the middle-income class householders have expanded and they are willing to pay getting the access for a fee levied higher education. Especially the students who are annually passing out from the international schools and the students who qualified for the state university entrance but cannot to enter the state university system due to lack of government resources are highly frustrated and treated unfairly according to the prevailing free education system. It is the direct responsibility of the government and the policy makers to develop a realistic strategy to address this issue before it is being another social unrest in the near future. However, this matter should be solved carefully without being jeopardized the existing free education system that brings the benefits for the vast majority of people in the country.

Despite there is an emerging demand and social pressure for establishing private universities in certain fields of studies, the concept of private universities has been severely criticized and opposed by the majority of state university students' movements and some of the social pressure 
groups. This has been one of the biggest issues with respect to Sri Lankan free education system, which hinders the education right of some people, for which academics and other policy makers need to pay an urgent attention. One of the solutions for this would be increasing the annual university entrance intake while allocating additional resources to universities to accommodate them. Sri Lanka currently has 15 state universities and considerable numbers of state higher education institutes that provide higher education opportunities. Establishing new national universities to accommodate for more students qualified for university education is another alternative solution in this regard. Nevertheless, if establishing new universities is a burden to the government recurrent budget owing to financial difficulties, it can be recommended to establish some fee levying government universities to provide higher education services at an affordable price.

According to Illeperuma (2015), a proper education system should suit our own need but has not changed according to the global changes in education. There are big criticisms from many parties that the school curricular is not updated to suit with the changing world and Sri Lankan school education is highly teacher centered rather than student centered limiting the opportunities for the students to engage in active and participatory learning process. It seems some of their criticisms are not constructive. In many cases, policy makers on school education at the national and provincial level have taken some satisfactory efforts to bring the school curricular suit to the modern world. Nevertheless, revising the school curricula is an ongoing continual process that should be carefully made on a timely basis by the experts in the government education service who have the required expertise in the education science rather than complete outsiders who are alien to the Sri Lankan education system.

Poor physical and mental health of the school students due to heavy workload, competition, and pressure from the parents for getting better results is another issue that has not been cared and concerned by the policy makers. So, it is recommended to consider the impact of the workload on the students' physical and mental health and divert the focus from classroom learning to activity-based learning. Educational scientists and psychological experts advise that students should be given adequate leisure time to contact with the environment. The annual school term calendar should be carefully set appropriately allocating adequate time for the holiday vacations for the students. For instance, the start of the Sinhala and Tamil new year vacation, which is the Sri Lankans traditional new year ceremony celebrated by many people in the country, drag down to the second week of the month of April, leaving the students have no adequate time to enjoy their new year with relatives and ease-off their mental pressure. 
Despite the government spends millions of funds on free education, it is seen that students have not been given the due recognition for the services they enjoyed from the free education. For example, this issue is very significant among the advanced level students who are studying in grade twelve and thirteen. This is mainly because students over reliance on the private tuition and attending to private institutes sacrificing their opportunity to study in the school classes. As a result, much more resources of government schools are underutilized, and it forgoes the opportunity of private college students who would really in need to enjoy the free education by attending government schools.

In the recent past, it seems that politicians tend to use government schools as ready-made places for political appointments for job schemes. School teachers play a very crucial role in the society in molding the future generation of any country. Teachers need to be carefully and scientifically selected for the school education service rather than selecting people for the sake of providing a job opportunity. It is recommended to establish the expected minimum standard for entry qualification for the school education system. This minimum education qualification would be a Degree or equivalent qualification from a recognize university or similar higher education institute.

During the recent past, school teachers have been less privileged in terms of their low salary, lack of training and development opportunities and no insurance cover, leaving them highly vulnerable in case of an emergency. So, it is recommended to increase the school teachers' salary to a level reasonably adequate to ensure attracting and retaining the right people in the school system and periodically offer them with training opportunities locally or overseas. Further, there should be a clear career development path for the school teachers and a transparent mechanism for the promotions such as promoting to the position of principal. Further, it is recommended that the periodic transfers of teachers should be made more transparent, scientific, and fair manner.

\section{Conclusion}

Education system of a country plays a crucial role in achieving a sustainable and integral development and it is treated as the backbone of any civilized society. Producing competent graduate, professional or technical expert and a responsible citizen enriched with social and cultural values, which eventually enhances the quality of a country's workforce, is one of the ways the education system contributes to the development of a country. Free education policy aims at providing equitable right to every child to access and benefits from education and making a responsible and resourceful citizen to the society. It is clear that all past and present governments of Sri Lanka have 
merely attempted to provide the education 'free of cost' rather than protecting the everyone's right to access to a 'quality education'. So, it can be concluded that both the 'equitable right' and the 'quality of education' has be compromised by the Sri Lankan education policy makers. Though, the free education policy has enabled Sri Lanka to be at the forefront in the South Asia in terms of literacy rate, school enrolment rate and gender parity in education, it has been criticized for not being progressively developed to cope with the changing world. At the policy making level, one of the key issues in the Sri Lankan education system is that the cabinet ministers tend to change the education policies on an add-hog basis as and when governments change. So, it is recommended to give more freedom and autonomy to the professional executives (i.e., state officers rather than cabinet ministers) who possess required competency and the expertise for developing and implementing consistent and long-lasting policies that best fit for the needs of the changing world. There is an increased concerned by both the academia and the educationalists on the allocation of funds from the annual budget that tends to reduce during the recent past. In order to achieve and maintain the expected quality of education it is recommend to increase the allocation of funds to state education up to $6 \%$ of the GDP. In particularly, lack of resources at rural schools, teacher centered learning environment, heavy student work load, lack of university entrance opportunity for those who qualify to enter universities from both public and private schools, changing education policies by the politicians on an ad hoc basis, lack of opportunity for school teachers for career development and low salary for school teachers, are some of the key issues that education policy makers and practitioners have to pay their close attention. It is recommended to policy makers to consider as to whether modern technology could be used to overcome majority of these issues more efficient and effective manner. For example, use of cloud computing to share teaching and learning material between rural and city schools, distance learning methods to allow the students from rural school to virtually attend and benefit from city school teachers' services etc.

In conclusion, it could be emphasized that the Sri Lankan education system requires an urgent reform or a revision on a holistic approach to address some key issues in the areas of policy making level, implementation level and supervisory and regulatory level. It is crucial that the country need to have an unambiguous long-term national policy on school and higher education clearly articulating its long-term goals and strategies. Thus, it is recommend that providing annually a $6 \%$ from the GDP for the state education; eliminating disparities between rural and urban popular schools by enhancing the facilities in the rural schools; timely revision of school curricular to best fit the changing world; promoting student centered, participatory and active learning environment; protecting the higher education right of the qualified students 
who are not absorbed by the state universities; protecting and enhancing the economic, career and social welfare life of the school teachers; among others, are the key areas that the policy makers must pay their urgent attention. Changing world, creates both challenges and opportunities and education policy makers are recommended to consider as to how to strategically fit both opportunities and threats to ensure that Sri Lankan education system is progressively moving ahead to meet the emerging challenges of the modern world.

\section{References:}

1. David T. Gamage., Prasad Setunga, (2011) Development of Sri Lankan System of Education- Third century BC to the 21 Century AD

2. Ganga M. Thilakarathne, (2006) Educational Opportunities for the Poor., Policy Brief 11., February 2006., Inter regional inequality facility.

3. Green, A., 1997. Education, Globalization and the Nation State. St. Martin's Press, Inc., Scholarly and Reference Division, 175 Fifth Avenue, New York, NY 10010.

4. Griffin, P., Care, E. and McGaw, B., 2012. The changing role of education and schools. In Assessment and teaching of 21st century skills (pp. 1-15). Springer Netherlands.

5. Jaison R. Abel., Richard Deitz, The Role of Colleges and Universities in Building Local Human Capital, Current issues in economics and finance, Volume 17, Number 6

6. Jayawardena Lakshman., On Sri Lanka's Free Education Crisis., Colombo Telegraph, May 21 $1^{\text {st }}, 2013$.

7. Manoharan N., Education System in Sri Lanka - I: The Problems, Institute of Peace and Conflicts Studies

8. Oliver A Illeperuma., Educational Reforms: Urgent National Need, Colombo Telegraph, October 16, 2015

9. Schultz, T.W., 1971. Investment in Human Capital. The Role of Education and of Research.

10. Steven Mintz, 2014, The shifting role of university system, Inside HigherED.

11. Van de Werfhorst, H.G., 2011. Skills, positional good or social closure? The role of education across structural-institutional labour market settings. Journal of Education and Work, 24(5), pp.521-548. 
Websites accessed

1. http://www.priu.gov.lk/news_update/Current_Affairs/ca201403/2014 0311mahindodaya_give_equal_educational_opportunities_rural_scho ols.htm

2. www.newyorkfed.org/research/current_issues

3. www.statistics.gov.lk/Pocket\%20Book/chap13.pdf 